\title{
A Candid Assessment of the Link between Oral Candida Containing Biofilms and Oral Cancer
}

\author{
J. Kang, Y. He, D. Hetzl, H. Q. Jiang, M. K. Jun, M. S. Jun, M. Khng, N. Cirillo, \\ M. J. McCullough* \\ Melbourne Dental School, The University of Melbourne, Parkville, Australia \\ Email: *m.mccullough@unimelb.edu.au
}

Received 17 November 2015; accepted 24 February 2016; published 29 February 2016

Copyright (C) 2016 by authors and Scientific Research Publishing Inc.

This work is licensed under the Creative Commons Attribution International License (CC BY). http://creativecommons.org/licenses/by/4.0/

(c) (i) Open Access

\section{Abstract}

An association between Candida and oral cancer has long been discussed in the literature and in particular Candida albicans has been proposed to play a significant role in the development of oral cancer. Although this organism is a common member of the oral mucosa and can cause a variety of oral mucosal lesions, the exact mechanisms by which $C$. albicans potentially causes the development of malignant disease still require much research. We have undertaken an extensive literature search to understand pathogenicity of $C$. albicans, including its virulence factors, its interactions with the host immune, how a dysregulation of the immune response can result in malignancy, and how a potential $C$. albicans specific cytokine response may be involved in oral carcinogenesis. We present here a candid assessment of the role of Candida in oral carcinogenesis and a hypothetical model about how this may occur. Finally, we present potential future research which is necessary to elucidate this role.

\section{Keywords}

Candida, Oral Cancer, Immunology, Cytokine Expression

\section{Introduction}

Head and neck cancer (HNC) is the 7th most prevalent cancer globally [1]. It is further divided into oro-/hypopharyngeal cancer, laryngeal cancer and oral cancer (OC). In 2012, OC accounted for more than half of newly reported cases of HNC, affecting two times more men than women [1]. Moreover, it contributed to 145,000

\footnotetext{
${ }^{*}$ Corresponding author.
} 
deaths worldwide in that same year, 77\% of which were in underdeveloped countries [1].

The established risk factors associated with OC include tobacco smoking, alcohol consumption, human papillomavirus, and gastric reflux. Moreover, infection and chronic inflammation play a significant role in cancer development [2].

Association between candidosis and precancerous oral neoplasia was first proposed in 1969 by Cawson and Williamson [3] [4]. Cawson proposed that Candida albicans had a significant role in oral mucosal carcinogenesis. C. albicans, a fungal organism, is a common member of the oral mucosa [5] [6]. Typical candidal infection is found within the oral and the vaginal mucosa. However, infection can occur in any types of the tissue within the body [5]. Candida spp. can cause a variety of oral mucosal lesions such as the precancerous oral candidal leukoplakia. It is an oral mucosal lesion with high incidence of malignant transformation in comparison to leukoplakia in general [7]-[9]. Transient or permanent Candida spp. residence is established in approximately 70\% of population with healthy oral tissues [10] [11]. Under conditions such as, but not limited to, diabetes, drug abuse, hyposalivation, and smoking, it exhibits pathogenic behaviour [12] [13]. Furthermore, there are differences in C. albicans strains found in healthy mucosa compared to precancerous and cancerous lesions [9]. Currently, the mechanisms employed by C. albicans in development of malignant cancers are still under research. To further investigate this matter, understanding pathogenicity of $C$. albicans, including its virulence factors and interactions with the host immune response, is necessary.

\section{Search Strategy}

An initial search using PubMed database, MEDLINE, and Google Scholar was performed using the text words contained in the research title. These keywords include "Candida", "Candida albicans", "biofilms", "keratinocyte", and "malignant”. Only articles from 2000-2015 written in English were included in this search. Articles were then selected for relevance upon reading titles and abstracts. A second search was conducted across all included databases, using more detailed keywords like "oral cancer", "head and neck cancer", "oral cavity cancer", "virulence”, “Th17”, "regulatory T cell”, “TGF Beta”, “Treg”, "MMP2”, “chronic inflammation”, "immune response", "invasion", "Matrigel”, and "ELISA". Lastly, the reference list from previously identified literature was used to search for additional studies with no restrictions on the year. Our searches considered both experimental and epidemiological study designs. Included studies are randomized controlled trials, non-randomized controlled trials, case control studies and analytical cross sectional studies.

\section{Oral Cancer and Candida albicans}

The role of C. albicans in oral mucosal carcinogenesis was proposed by Cawson in 1969. He stated that the presence of Candida spp. is a non-dependent risk factor for the development of oral carcinoma [4]. His findings were validated by two significant studies. Firstly, Nagy et al. in 1998 found an increase in frequency of C. albicans in biofilms of oral squamous cell carcinoma (OSCC) tumour sites [14]. Secondly, McCullough et al. in 2002 proposed that oral yeast carriage was correlated with both existence and severity of oral epithelial dysplastic and neoplastic development [15]. In addition to these two studies, Sanjaya et al., Alnuami et al., Arzmi et al., Norgaard et al., Rodriguez et al., found a strong relationship between the presence of C. albicans in the oral cavity and the malignancy of precancerous lesions [6] [17]-[19]. This is consistent with research conducted by Williams et al., who showed that the elimination of Candida spp. from infected oral tissue reduced cancerous cell counts (2011).

A case-control study conducted in Italy found association of candidosis with a six-fold increase in oral cancer [20]. The result of this study, however, was unprecedented and was not supported within the literature. In addition, the self-reporting data recruitment methodology of this particular study may pose questions to the validity of the data.

The role of C. albicans in oral mucosal carcinogenesis, however, did not go uncontended. Sitheeque \& Samarnayake rebuked the independent role of Candida spp. in carcinogenesis arguing that evidence did not point towards a causal relationship between the two [21]. In 2011, Sanjaya et al. proposed that C. albicans had an indirect causal role in oral cancer along with other factors such as tobacco and alcohol usage [6].

Overall, studies from this review found dichotomous perspectives regarding the presence of Candida spp. as a non-dependent risk factor for the development of oral carcinoma [15] [21] [22]. The exact involvement of other factors contributing to the initiation of carcinogenesis with Candida spp. also remains unclear [6]. Additional 
research is required to establish the validity of both claims. Furthermore, searches within the literature presented a correlation between C. albicans and the malignancy of precancerous lesions [6] [16]-[19]. A direct link between precancerous to cancerous lesions is absent in the literature and thus may also present as an area of research interest.

Recent studies examining the role of Candida spp. in malignancy focus on the identification of specific strains of C. albicans eliciting hyperplasia. A 1987 study by Krogh found that C. albicans biotypes isolated from candidal leukoplakia are different from those isolated from normal oral mucosa [23]. This study suggested that malignant development of pre-cancer may be related to certain strains of C. albicans. In 2014, a 154-patient study in Australia by Alnuami et al. demonstrated a variance in resident Candida strains between oral cancer/pre-oral cancer patients and non-oral cancer patients [9]. The author concluded that there is a genotypic specificity in oral carcinogenesis [9].

\section{Virulence Factors of $C$. albicans}

The virulence of $C$. albicans is determined by how well it can successfully colonize the host. The pathogenicity of $C$. albicans depends on numerous factors such as phenotypic switching, dimorphism, adhesive properties, extracellular enzyme production, and biofilm formation.

C. albicans has the ability to switch between two phenotypes, white or opaque cells [24]-[26]. White cells are round or ovoid in shape whereas the opaque cells are elongated [24]. The rapid phenotypic switching allows $C$. albicans to adapt to ever-changing environments [27]. This mechanism helps C. albicans to evade the host's defenses and allows it to alter its virulence traits such as drug resistance [26].

Not only can C. albicans change its phenotype but also its morphology. Depending on different gene expressions, it can switch between yeast and hyphae forms [28]. Hyphae, the main mode of vegetative fungal growth, are characterized by the presence of septa within the filaments often surrounded by cell walls made of chitin. They allow invasion of epithelial tissues resulting in host cell damage [29]. The dimorphic nature of C. albicans, therefore, is an important virulence factor.

Another major attribute for virulence of C. albicans is hydrophobicity [30]. Successful adhesion minimizes host clearance and increases pathogenicity of $C$. albicans [31]. The hydrophobic nature of $C$. albicans in combination with the presence of adhesins such as agglutinin-like sequence (ALS) gene family and hyphal wall protein (HWP1) promote its adhesion to epithelial surfaces [32].

In addition, C. albicans can produce extracellular enzymes that are harmful to host cells [22]. The most important enzymes are aspartyl proteinases (SAPs) and phospholipases (PLs). SAPs play a crucial role in the initial penetration and production of nitrogen during colonization of keratinized cells. PLs, on the other hand, cause lysis leading to cell death by disturbing cellular membranes [7].

The most important virulence factor of $C$. albicans for the purpose of this study is the formation of biofilm. Formation of biofilm leads to an increase in diversity of oral microorganisms inducing ecological changes. An oral biofilm is formed when the microorganism adheres to a surface in an aqueous environment and begins to excrete extracellular material [33]. C. albicans can form biofilm on both hard and soft tissues of the oral cavity [34]. Formation of biofilms is beneficial to C. albicans as it allows protection from the host defense and antifungal agents enhancing its virulence and broadening its habitat range. In addition, biofilms allow C. albicans to interact with other microorganisms (refer to Table 1). Factors affecting the formation of oral biofilm include substratum, gingival crevicular fluid and saliva production [35]. In conclusion, formation of biofilm alters the microbiota of the oral cavity and causes disease by disrupting the host immune response. However, the exact molecular mechanisms governing biofilm formation and pathogenicity are yet to be discovered.

\section{C. albicans Immune Response}

Both the host immune response and the virulence factors of $C$. albicans can disrupt the homeostatic balance between C. albicans and its host. The complex mechanism of an anti-C. albicans response has been investigated by many researchers.

Recent literature shows that the immune response to oral C. albicans is dependant upon its different life stages. A balance between T helper 17 (Th17) and regulatory T cells (Tregs) is required to controlC. albicans in the oral cavity [36]. However, this is different from the other parts of the body. For example in the gastrointestine, the suppression of Th17 by Tregs works as a protective mechanism [36]. Conversely in the oral cavity, it is 
Table 1. Interaction of C. albicans and microorganisms in oral biofilm (Arzmin.d.).

\begin{tabular}{|c|c|c|}
\hline Microorganism & Functions & References \\
\hline S. sanguis & $\begin{array}{l}\text { Decreased adherence to acrylic surfaces and } \\
\text { human buccal epithelial cells }\end{array}$ & $\begin{array}{l}\text { Nair and Samaranayake } \\
\text { (1996) }\end{array}$ \\
\hline $\begin{array}{l}\text { A. naeslundii } \\
\text { S. gordonii } \\
\text { S. sanguis } \\
\text { S. aureus }\end{array}$ & Decreased adherence to acrylic surface & Millsap et al. (2000) \\
\hline P. aeruginosa & $\begin{array}{l}\text { Formation of dense biofilm. Obtained nutrient } \\
\text { from hyphae of } C \text {. albicans }\end{array}$ & Hogan and Kotler (2002) \\
\hline P. gingivalis & $\begin{array}{l}\text { Decreased adherence to acrylic surfaces and } \\
\text { human buccal epithelial cells }\end{array}$ & $\begin{array}{l}\text { Nair and Samaranayake } \\
\text { (1996) }\end{array}$ \\
\hline P. intermedia & Suppression of germ tube formation & Nair et al. (2001) \\
\hline
\end{tabular}

the promotion of Th17 differentiation by Tregs that is protective [36].

The major cells involved in initial detection of $C$. albicans include keratinocytes, macrophages and dendritic cells (DCs). These cells can detect pathogen associated molecular patterns (PAMPs) via pattern recognition receptors (PRRs) [37]. Various morphological forms of C. albicans are associated with diverse numbers of PAMPs, allowing different and appropriate immune responses to be mounted [38]. This has been observed with epithelial cells that are capable of differentiating between the commensal yeast form and the pathogenic hyphae form of C. albicans [38]. Studies of mice have also shown that inadequate Treg expansion displays inflammation-associated pathology when infected with C. albicans [39].

Currently, it is recognized that the maintenance of low fungal burden is mainly the result of the antimicrobial action of neutrophils [37]. The recruitment of neutrophils is normally fast acting, however, an adequate response is only possible with the aid of Th17 cells [40]. The mounting of Th17 response begins with the processing of $C$. albicans antigens by DCs that have been stimulated by their PRRs. Upon processing and presentation, naive $\mathrm{CD}^{+} \mathrm{T}$ cells differentiate into Th17 cells with the help of Tregs. They are then recruited to the site of infection. Upon activation, they proceed to secrete the appropriate cytokines. The principal cytokine secreted is IL-17, alongside other pro-inflammatory cytokines that propagate a neutrophil driven response. IL-17 can indirectly promote a neutrophil response by inducing epithelial cells to produce IL-8, a neutrophil recruiting chemokine [40]. Neutrophils then proceed to control the fungal infection via matrix metalloproteinase (MMPs), phagocytosis, and neutrophil extracellular traps (NETs), adjunct to other effector molecules [41]. Figure 1 gives a graphic representation of the proposed immunological response to oral C. albicans.

\section{Cancer and Dysregulated Immune Response}

One hallmark of cancer is the ability to avoid immune surveillance [42]. An effective way of escaping immune surveillance is through a tumour microenvironment. This consists of immunosuppressive factors such as IL-10 and TGF- $\beta$ that are secreted by tumour cells or Tregs [42]. Furthermore, these cells can promote production of pro-angiogenic M2 phenotype macrophages [39]. As a result, concurrent infections may fail to be cleared giving rise to chronic inflammation. This scenario has been shown with Helicobacter pylori and it is now clearly established that $H$. pylori is carcinogenic by promoting a chronic inflammatory state [43]. This can be problematic as recruited immune cells secrete pro-inflammatory cytokines that constantly stimulate surrounding cells [44]. Normally, pro-inflammatory cytokines promote NF-kB expression in immune and epithelial cells. NF-kB is a transcription factor and plays a vital role in immune development [45] [46]. Furthermore, NF-kB expression has been shown to play role in oncogenesis [47]. However, NF-kB can also be expressed by tumour cells to activate anti-apoptotic molecules like Bcl-2 [48]. Constant presence of pro-inflammatory molecules due to chronic inflammation allows activation of such pathways promoting a carcinogenic environment [49].

\section{C. albicans Immune Response and Cancer}

The correlations of $C$. albicans with oral cancer lead us to speculate the importance of the host to be able to 


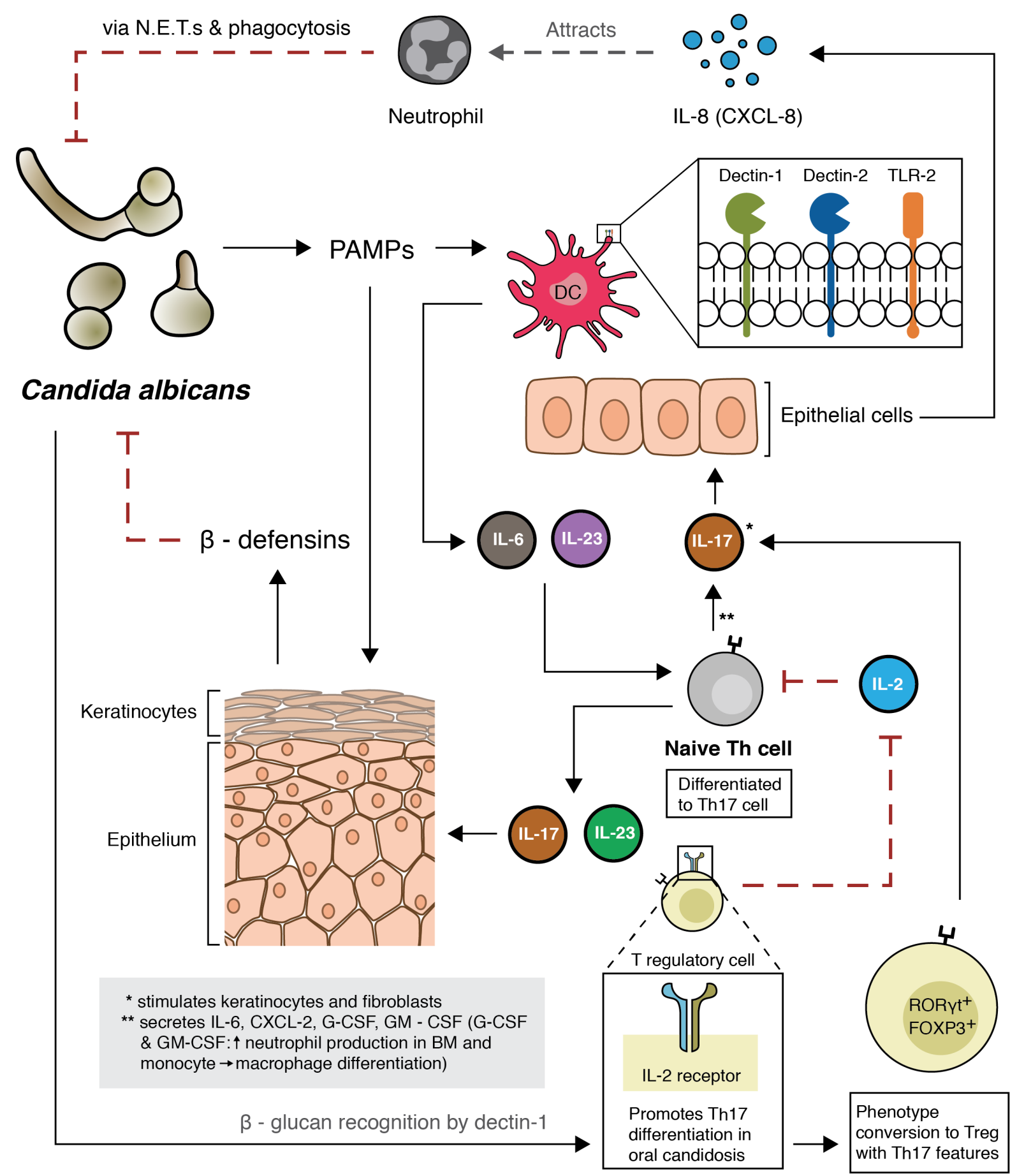

Figure 1. The immune response against Candida albicans within the oral cavity involving Th17 and Treg. The immune response against $C$. albicans begins with recognition of PAMPs by PRRs (TLR-2, Dectin-1, Dectin-2). This allows differentiation of $\mathrm{CD}^{+} \mathrm{T}$ helper cells to Th17 cells with the help of dendritic cells (DCs). Th17 cells subsequently propagate a neutrophil response at the site of infection by increasing neutrophil production in the bone marrow (via G-CSF and GM-CSF). They also indirectly recruit neutrophils by promoting epithelial cells to secrete IL-8, keratinocytes and fibroblasts. Neutrophils then proceed to attack C. albicans via mechanisms including phagocytosis and neutrophil extracellular traps (N.E.T.s). Moreover, Tregs aid in Th17 response. Tregs are speculated to help Th17 by sequestering IL-2 (Th17 differentiation inhibitor) via CD25 (IL-2 receptor). It has been observed that Tregs can also undergo phenotypic conversion to display Th17 features. This further contributes to IL-17 production. Detection of PAMPs by keratinocytes along with IL-17 and IL-23 stimulation also enhances keratinocyte secretion of anti-fungal $\beta$-defensins. 
combat the microorganism in order to prevent the disease. Thus, an immune response against C. albicans, opposing the virulence factors that allow it to successfully colonize is vital. A disruption to Th17 and Treg cell balance in oral $C$. albicans infection can result in an inadequate immune response and may lead to a chronic inflammatory state or over recruitment of Treg cells. The presence of excessive pro-inflammatory cytokines in chronic inflammation may promote tumour growth in the oral cavity due to the overlapping pathways involved in both the immune response and cancer cell survival. An immunosuppressive tumour microenvironment with possible overrepresentation of Treg cells also has the potential to promote tumour growth within the oral cavity.

Although the immune response to fungi has been thoroughly researched, there is a lack of literature assessing how coexistence of $C$. albicans with other microorganisms in oral biofilms alters the immune response. Hopefully, further studies will shed light onto the possible mechanisms how $C$. albicans can be carcinogenic, similarly to $H$. pylori. A difference in amount of molecules such as MMP-2, MMP-9 and TGF- $\beta$ found in carcinogenic $C$. albicans biofilms could indicate an overrepresentation of one arm of a dysregulated immune response.

\section{Cytokines and Carcinogenesis}

Tumour growth and invasion involves multiple interactions between tumour cells and stromal cells. One of the many stromal events that may lead to carcinogenesis is the secretion of cytokines [50].

TGF- $\beta$ is a pleiotropic cytokine. It can be anti-carcinogenic or carcinogenic depending on the surrounding microenvironment. The effects of TGF- $\beta$ in carcinogenesis have been heavily studied and well proven [51]-[53]. A change in TGF-signaling pathway, either excessive or deficient, will cause cancer [51].

In a study looking at TGF- $\beta$ receptor type II (T $\beta$ RII) knock-out mice, loss of TGF- $\beta$ pathways resulted in development of squamous cell carcinomas [52]. In human trials, deletion or mutation of TGF- $\beta$ receptors are associated with more invasive forms or worse prognosis of colorectal, prostate, breast and bladder cancers [53]. Moreover, elevated levels of TGF- $\beta$ mRNA and protein are observed in gastric carcinoma, lung cancer, colorectal and prostate cancers [54].

A signaling change in TGF- $\beta$ pathways has been associated with human carcinogenesis.An early study found an increased endogenous production of TGF- $\beta$ by spleen cells soon after systemic infection of healthy mice with a live vaccine strain of $C$. albicans [55]. Yet, no studies have been conducted examining TGF- $\beta$ production in response to local oral keratinocytes infections with $C$. albicans.

\section{Effect of $C$. albicans on OSCC Initiation and Progression}

Tumour invasion, metastasis, and angiogenesis all require controlled degradation of extracellular matrix (ECM). An increased expression of matrix metalloproteinases (MMPs) has a positive association with tumor invasion and metastasis of malignant tumors of different histogenetic origin [56]. Among the family of MMPs, the action of gelatinases MMP-2 and MMP-9, especially in active forms, promote the metastatic potential of tumour cells by digesting type IV collagen and initiating the destruction of the basement membrane (BM) [57].

However, studies on direct influences of $C$. albicans on the production of MMP2 and MMP9 showed contradicting results. An increase in MMP-2 expression was found in engineered human oral mucosa following infection with $C$. albicans, without an increase in protein production. The author postulated that this result can be explained by the fact that while $C$. albicans activate the MMP-2 gene, the protein is immediately used by the yeast as a substrate [58]. However, the exact mechanism remains unknown. In the same study, a significant decrease in the secretion of a tissue metallopeptidase inhibitor 2 (TIMP-2) is evident from the same cell line. The author thus speculated that down-regulating TIMP-2 allows an increase in MMP-9 levels, contributing to the tissue disruption and facilitating C. albicans invasion. Furthermore, a more recent study has demonstrated that MMP-2 initiates keratinocyte dis-cohesion and epithelial invasion into collagen gels, thus leading to cancer associated fibroblasts with a more aggressive oral cancer phenotype [59].

Moreover, elevated expression and activation of MMP-2 and MMP-9 are reported to be related to tumor aggressiveness and poor prognosis of patient survival as they cause destruction to ECM and BM, facilitating angiogenesis, tumor invasion, and metastasis. However, a recent in vitro studyhas shown a contradicting finding of increased MMP-2 gene expression without an increase in protein in engineered human oral mucosa following infection with $C$. albicans, which has mystified the issue.

Further research in examination of activated forms of MMPs in C. albicans infected oral mucosa is very important to understand this process. We hope a deeper understanding of the pro-invasive effect of C. albicans can 
help inform future treatment for oral candidal-based lesions and tumours.

\section{Conclusions and Future Research}

This extensive review of the literature leads us to propose that Candida, especially C. albicans, plays a significant role in the development of OSCC via its interaction with epithelial cells, resulting in production of epithelial cytokines and MMPs and an epithelial pro-invasive phenotype. This role is likely to occur when C. albicans forms as a biofilm. Further, this carcinogenic effect is likely linked with both the form of candidal growth (whether yeast or hyphal) and the interactions with other microbial species in a mixed biofilm.

Thus, further research is needed to assess the invasive behaviour of oral keratinocytes when grown in contact with a range of oral biofilms that contain C. albicans. The pro-invasiveness of the oral keratinocytes could be assessed via the expression of specific pro-invasive molecules, migration through extra-cellular matrix and basement membrane and the degree of epithelial-mesenchymal transition, all of which may be involved in the development of oral cancer.

It is anticipated that these studies will enhance our understanding of the role of $C$. albicans in oral carcinogenesis, as well as a greater understanding of the critical role of biofilm and epithelial interaction. It may well be that such an advance in our understanding opens new mechanism in the prevention and treatment of oral cancer.

\section{References}

[1] Ferlay, J., Soerjomataram, I., Dikshit, R., Eser, S., Mathers, C., Rebelo, M., et al. (2015) Cancer Incidence and Mortality Worldwide: Sources, Methods and Major Patterns in GLOBOCAN 2012. International Journal of Cancer (Journal International du Cancer), 136, E359-E386.

[2] Bakri, M.M., Hussaini, H.M., Holmes, A.R., Cannon, R.D. and Rich, A.M. (2010) Revisiting the Association between Candidal Infection and Carcinoma, Particularly Oral Squamous Cell Carcinoma. Journal of Oral Microbiology, 2, 1.

[3] Williamson, D.M. (1969) Chronic Hyperplastic Candidiasis and Squamous Carcinoma. British Journal of Dermatology, 81, 125-127. http://dx.doi.org/10.1111/j.1365-2133.1969.tb15992.x

[4] Cawson, R. (1969) Leukoplakia and Oral Cancer. Proceedings of the Royal Society of Medicine, 62, 610.

[5] Gall, F., Colella, G., Di Onofrio, V., Rossiello, R., Angelillo, I.F. and Liguori, G. (2013) Candida spp. in Oral Cancer and Oral Precancerous Lesions. New Microbiol, 36, 283-288.

[6] Sanjaya, P., Gokul, S., Patil, B.G. and Raju, R. (2011) Candida in Oral Pre-Cancer and Oral Cancer. Medical Hypotheses, 77, 1125-1128. http://dx.doi.org/10.1016/j.mehy.2011.09.018

[7] Scully, C., Ei-Kabir, M. and Samaranayake, L.P. (1994) Candida and Oral Candidosis: A Review. Critical Reviews in Oral Biology \& Medicine, 5, 125-57.

[8] Reibel, J. (2003) Prognosis of Oral Pre-Malignant Lesions: Significance of Clinical, Histopathological, and Molecular Biological Characteristics. Critical Reviews in Oral Biology \& Medicine, 14, 47-62. http://dx.doi.org/10.1177/154411130301400105

[9] Alnuaimi, A.D., O’Brien-Simpson, N.M., Reynolds, E.C. and McCullough, M.J. (2013) Clinical Isolates and Laboratory Reference Candida Species and Strains Have Varying Abilities to Form Biofilms. FEMS Yeast Research, 13, 689-699. http://dx.doi.org/10.1111/1567-1364.12068

[10] Thein, Z.M., Samaranayake, Y.H., Samaranayake, L.P. (2007) In Vitro Biofilm Formation of Candida albicans and Non-albicans Candida Species under Dynamic and Anaerobic Conditions. Archives of Oral Biology, 52, 761-767. http://dx.doi.org/10.1016/j.archoralbio.2007.01.009

[11] Mitchell, B.M., Wu, T.G., Jackson, B.E. and Wilhelmus, K.R. (2007) Candida albicans Strain-Dependent Virulence and Rim13p-Mediated Filamentation in Experimental Keratomycosis. Investigative Ophthalmology \& Visual Science, 48, 774-780. http://dx.doi.org/10.1167/iovs.06-0793

[12] Jenkinson, H.F. and Douglas, L.J. (2002) Interactions between Candida Species and Bacteria in Mixed Infections. In: Brogden, K. and Guthmiller, J., Eds., Polymicrobial Diseases, ASM Press, Washington DC, 357-373. http://dx.doi.org/10.1128/9781555817947.ch18

[13] Akpan, A. and Morgan, R. (2002) Oral Candidiasis. Postgraduate Medical Journal, 78, 455-459. http://dx.doi.org/10.1136/pmj.78.922.455

[14] Nagy, K., Sonkodi, I., Szöke, I., Nagy, E. and Newman, H. (1998) The Microflora Associated with Human Oral Carcinomas. Oral Oncology, 34, 304-308. http://dx.doi.org/10.1016/S1368-8375(98)80012-2

[15] McCullough, M., Jaber, M., Barrett, A., Bain, L., Speight, P. and Porter, S. (2002) Oral Yeast Carriage Correlates with Presence of Oral Epithelial Dysplasia. Oral Oncology, 38, 391-393. http://dx.doi.org/10.1016/S1368-8375(01)00079-3 
[16] Alnuaimi, A.D., Wiesenfeld, D., O’Brien-Simpson, N.M., Reynolds, E.C. and McCullough, M.J. (2015) Oral Candida Colonization in Oral Cancer Patients and Its Relationship with Traditional Risk Factors of Oral Cancer: A Matched Case-Control Study. Oral Oncology, 51, 139-145. http://dx.doi.org/10.1016/j.oraloncology.2014.11.008

[17] Arzmi, M., Alshwaimi, E., Harun, W.W., Razak, F.A., Farina, F., McCullough, M., et al. (2014) Gaining More Insight into the Determinants of Candida Species Pathogenicity in the Oral Cavity. European Journal of Inflammation, 12, 227-235.

[18] Nørgaard, M., Thomsen, R.W., Farkas, D.K., Mogensen, M.F. and Sørensen, H.T. (2013) Candida Infection and Cancer Risk: A Danish Nationwide Cohort Study. European Journal of Internal Medicine, 24, 451-455. http://dx.doi.org/10.1016/j.ejim.2013.02.017

[19] Rodriguez, M.J., Schneider, J., Moragues, M.D., Martinez-Conde, R., Ponton, J. and Aguirre, J.M. (2007) CrossReactivity between Candida albicans and Oral Squamous Cell Carcinoma Revealed by Monoclonal Antibody C7. Anticancer Research, 27, 3639-3643.

[20] Talamini, R., Vaccarella, S., Barbone, F., Tavani, A., La Vecchia, C., Herrero, R., et al. (2000) Oral Hygiene, Dentition, Sexual Habits and Risk of Oral Cancer. British Journal of Cancer, 83, 1238-1242. http://dx.doi.org/10.1054/bjoc.2000.1398

[21] Sitheeque, M. and Samaranayake, L. (2003) Chronic Hyperplastic Candidosis/Candidiasis (Candidal Leukoplakia). Critical Reviews in Oral Biology \& Medicine, 14, 253-267. http://dx.doi.org/10.1177/154411130301400403

[22] Naglik, J., Albrecht, A., Bader, O. and Hube, B. (2004) Candida albicans Proteinases and Host/Pathogen Interactions. Cellular Microbiology, 6, 915-926. http://dx.doi.org/10.1111/j.1462-5822.2004.00439.x

[23] Krogh, P. (1990) The Role of Yeasts in Oral Cancer by Means of Endogenous Nitrosation. Acta Odontologica, 48, 8588. http://dx.doi.org/10.3109/00016359009012738

[24] Anderson, J.M. and Soll, D.R. (1987) Unique Phenotype of Opaque Cells in the White-Opaque Transition of Candida albicans. Journal of Bacteriology, 169, 5579-5588.

[25] Jones, S., White, G. and Hunter, P. (1994) Increased Phenotypic Switching in Strains of Candida albicans Associated with Invasive Infections. Journal of Clinical Microbiology, 32, 2869-2870.

[26] Vargas, K.G., Srikantha, R., Holke, A., Sifri, T., Morris, R. and Joly, S. (2004) Candida albicans Switch Phenotpes Display Differential Levels of Fitness. Medical Science Monitor, 10, BR198-BR206.

[27] Williams, D. and Lewis, M. (2011) Pathogenesis and Treatment of Oral Candidosis. Journal of Oral Microbiology, 3, 1. http://dx.doi.org/10.3402/jom.v3i0.5771

[28] Sudbery, P., Gow, N. and Berman, J. (2004) The Distinct Morphogenic States of Candida albicans. Trends in Microbiology, 12, 317-324. http://dx.doi.org/10.1016/j.tim.2004.05.008

[29] Jackson, A.P., Gamble, J.A., Yeomans, T., Moran, G.P., Saunders, D., Harris, D., et al. (2009) Comparative Genomics of the Fungal Pathogens Candida dubliniensis and Candida albicans. Genome Research, 19, 2231-2244. http://dx.doi.org/10.1101/gr.097501.109

[30] Calderone, R.A. and Braun, P.C. (1991) Adherence and Receptor Relationships of Candida albicans. Microbiological Reviews, 55, 1-20.

[31] Hazen, K.C. (1989) Participation of Yeast Cell Surface Hydrophobicity in Adherence of Candida albicans to Human Epithelial Cells. Infection and Immunity, 57, 1894-1900.

[32] Cotter, G. and Kavanagh, K. (2000) Adherence Mechanisms of Candida albicans. British Journal of Biomedical Science, 57, 241-249.

[33] Hojo, K., Nagaoka, S., Ohshima, T. and Maeda, N. (2009) Bacterial Interactions in Dental Biofilm Development. Journal of Dental Research, 88, 982-990. http://dx.doi.org/10.1177/0022034509346811

[34] Mayer, F.L., Wilson, D. and Hube, B. (2013) Candida albicans Pathogenicity Mechanisms. Virulence, 4, 119-128. http://dx.doi.org/10.4161/viru.22913

[35] Samaranayake, L., McCourtie, J. and MacFarlane, T. (1980) Factors Affecting the In-Vitro Adherence of Candida albicans to Acrylic Surfaces. Archives of Oral Biology, 25, 611-615. http://dx.doi.org/10.1016/0003-9969(80)90076-X

[36] Whibley, N. and Gaffen, S.L. (2014) Brothers in Arms: Th17 and Treg Responses in Candida albicans Immunity. PLoS Pathogens, 10, e1004456. http://dx.doi.org/10.1371/journal.ppat.1004456

[37] Moyes, D.L. and Naglik, J.R. (2011) Mucosal Immunity and Candida albicans Infection. Clinical and Developmental Immunology, 2011, Article ID: 346307.

[38] Moyes, D.L., Runglall, M., Murciano, C., Shen, C., Nayar, D., Thavaraj, S., et al. (2010) A Biphasic Innate Immune MAPK Response Discriminates between the Yeast and Hyphal Forms of Candida albicans in Epithelial Cells. Cell Host \& Microbe, 8, 225-235. http://dx.doi.org/10.1016/j.chom.2010.08.002 
[39] Mantovani, A., Sozzani, S., Locati, M., Allavena, P. and Sica, A. (2002) Macrophage Polarization: Tumor-Associated Macrophages as a Paradigm for Polarized M2 Mononuclear Phagocytes. Trends in Immunology, 23, 549-555. http://dx.doi.org/10.1016/S1471-4906(02)02302-5

[40] Conti, H.R., Shen, F., Nayyar, N., Stocum, E., Sun, J.N., Lindemann, M.J., et al. (2009) Th17 Cells and IL-17 Receptor Signaling Are Essential for Mucosal Host Defense against Oral Candidiasis. The Journal of Experimental Medicine, 206, 299-311. http://dx.doi.org/10.1084/jem.20081463

[41] Byrd, A.S., O’Brien, X.M., Johnson, C.M., Lavigne, L.M. and Reichner, J.S. (2013) An Extracellular Matrix-Based Mechanism of Rapid Neutrophil Extracellular Trap Formation in Response to Candida albicans. The Journal of Immunology, 190, 4136-4148. http://dx.doi.org/10.4049/jimmunol.1202671

[42] Hanahan, D. and Weinberg, R.A. (2011) Hallmarks of Cancer: The Next Generation. Cell, 144, 646-674. http://dx.doi.org/10.1016/j.cell.2011.02.013

[43] Wroblewski, L.E., Peek, R.M. and Wilson, K.T. (2010) Helicobacter Pylori and Gastric Cancer: Factors That Modulate Disease Risk. Clinical Microbiology Reviews, 23, 713-739. http://dx.doi.org/10.1128/CMR.00011-10

[44] Shacter, E. and Weitzman, S.A. (2002) Chronic Inflammation and Cancer. Oncology, 16, 217-232.

[45] Bacurele, P. and Henkel, T. (1994) Functions and Activation of NF- $\kappa$ B in the Immune System. Annual Review of Immunology, 28, 121-127.

[46] Tripathi, P. and Aggarwal, A. (2006) NF- $\kappa$ B Transcription Factor: A Key Player in the Generation of Immune Response. Current Science, 90, 519-531.

[47] Dolcet, X., Llobet, D., Pallares, J. and Matias-Guiu, X. (2005) NF- $\kappa$ B in Development and Progression of Human Cancer. Virchows Archiv, 446, 475-482. http://dx.doi.org/10.1007/s00428-005-1264-9

[48] Pikarsky, E., Porat, R.M., Stein, I., Abramovitch, R., Amit, S., Kasem, S., et al. (2004) NF- $\kappa$ B Functions as a Tumour Promoter in Inflammation-Associated Cancer. Nature, 431, 461-466. http://dx.doi.org/10.1038/nature02924

[49] Mantovani, A., Allavena, P., Sica, A. and Balkwill, F. (2008) Cancer-Related Inflammation. Nature, 454, 436-444. http://dx.doi.org/10.1038/nature07205

[50] Edna, Z.P.C., Kodappully, S.S., Muthu, K.S., Frank, A. and Gautam, S. (2015) Analysis of the Intricate Relationship between Chronic Inflammation and Cancer. Biochemical Journal, 468, 1-15. http://dx.doi.org/10.1042/BJ20141337

[51] Landskron, G., De la Fuente, M., Thuwajit, P., Thuwajit, C. and Hermoso, M.A. (2014) Chronic Inflammation and Cytokines in the Tumor Microenvironment. Journal of Immunology Research, 2014, Article ID: 149185.

[52] Guasch, G., Schober, M., Pasolli, H.A., Conn, E.B., Polak, L. and Fuchs, E. (2007) Loss of TGF $\beta$ Signaling Destabilizes Homeostasis and Promotes Squamous Cell Carcinomas in Stratified Epithelia. Cancer Cell, 12, 313-327. http://dx.doi.org/10.1016/j.ccr.2007.08.020

[53] Levy, L. and Hill, C.S. (2006) Alterations in Components of the TGF- $\beta$ Superfamily Signaling Pathways in Human Cancer. Cytokine \& Growth Factor Reviews, 17, 41-58. http://dx.doi.org/10.1016/j.cytogfr.2005.09.009

[54] Bierie, B. and Moses, H.L. (2006) TGF- $\beta$ and Cancer. Cytokine \& Growth Factor Reviews, 17, 29-40. http://dx.doi.org/10.1016/j.cytogfr.2005.09.006

[55] Spaccapelo, R., Romani, L., Tonnetti, L., Cenci, E., Mencacci, A., Del Sero, G., et al. (1995) TGF-Beta Is Important in Determining the in Vivo Patterns of Susceptibility or Resistance in Mice Infected with Candida albicans. The Journal of Immunology, 155, 1349-1360.

[56] Westermarck, J. and Kähäri, V.-M. (1999) Regulation of Matrix Metalloproteinase Expression in Tumor Invasion. The FASEB Journal, 13, 781-792.

[57] Fan, H.-X., Li, H.-X., Chen, D., Gao, Z.-X. and Zheng, J.-H. (2012) Changes in the Expression of MMP2, MMP9, and ColIV in Stromal Cells in Oral Squamous Tongue Cell Carcinoma: Relationships and Prognostic Implications. Journal of Experimental \& Clinical Cancer Research, 31, 90. http://dx.doi.org/10.1186/1756-9966-31-90

[58] Claveau, I., Mostefaoui, Y. and Rouabhia, M. (2004) Basement Membrane Protein and Matrix Metalloproteinase Deregulation in Engineered Human Oral Mucosa Following Infection with Candida albicans. Matrix Biology, 23, 477486. http://dx.doi.org/10.1016/j.matbio.2004.08.006

[59] Hassona, Y., Cirillo, N., Heesom, K., Parkinson, E. and Prime, S. (2014) Senescent Cancer-Associated Fibroblasts Secrete Active MMP-2 That Promotes Keratinocyte Dis-Cohesion and Invasion. British Journal of Cancer, 111, 12301237. http://dx.doi.org/10.1038/bjc.2014.438 